\title{
Complex I and ATP Content Deficiency in Lymphocytes from Friedreich's Ataxia
}

\author{
Mohammad Mehdi Heidari, Massoud Houshmand, Saman Hosseinkhani, \\ Shahriar Nafissi, Mehri Khatami
}

\begin{abstract}
Background: Friedreich's ataxia (FRDA) is an inherited recessive disorder characterized by progressive neurological disability and heart abnormalities. A deficiency in the protein frataxin causes this disease. Frataxin deficiency leads to progressive iron accumulation in mitochondria, excessive free radical production and dysfunction of respiratory chain complexes. The expansion (GAA) repeat in the first intron causes decreased frataxin expression by interfering with transcription. Methods: Activity of mitochondrial respiratory chain complex I (measured as NADH ferricyanide reductase) and intracellular ATP measurement was performed on lymphocyte of FRDA patients $(n=12)$ and control subjects $(n=25)$. Results: Our findings showed that complex I activity and intracellular ATP were significantly reduced $(\mathrm{P}=0.001)$ in patients compared with controls and we found strong correlation between complex I activity and intracellular ATP content in FRDA patients $(\mathrm{r}=0.93 ; \mathrm{P}<0.002) .8 .6$ and $9.0 \mathrm{~kb}$ deletion in mtDNA was detected in 9 patients out of $12(75 \%)$ by multiplex polymerase chain reaction (PCR) and Southern blot analysis. Conclusions: This study suggested that a biochemical defect in complex I activity and ATP production, which may be due to iron accumulation in mitochondria, can be involved in age of onset of FRDA.
\end{abstract}

RÉSUMÉ: Déficit en complexe I et en ATP dans les lymphocytes de patients atteints de l'ataxie de Friedreich. Contexte : L'ataxie de Friedreich (AF) est une maladie récessive caractérisée par une atteinte neurologique progressive et des anomalies cardiaques. La cause de cette maladie est un déficit d'une protéine, la frataxine, provoquant une accumulation progressive de fer dans les mitochondries, une production excessive de radicaux libres et une dysfonction des complexes de la chaîne respiratoire. L'expansion d'une répétition (GAA) dans le premier intron provoque une diminution de l'expression du gène de la frataxine en interférant avec sa transcription. Méthodes : L'activité du complexe I de la chaîne respiratoire mitochondriale (par mesure de la NADH ferricyanide réductase ) et la mesure de l'ATP intracellulaire ont été évaluées dans des lymphocytes de patients atteints d'AF $(\mathrm{n}=12)$ et de sujets témoins $(\mathrm{n}=25)$. Résultats $:$ L'activité du complexe I et l'ATP intracellulaire étaient significativement diminués $(\mathrm{p}=0,001)$ chez les patients par rapport aux sujets témoins et nous avons observé une corrélation étroite entre l'activité du complexe I et l'ATP intracellulaire chez les patients atteints d'AF $(r=0,93 ; \mathrm{p}<0,002)$. Chez 9 des 12 patients $(75 \%)$, nous avons détecté une délétion de 8,6 et de 9,0 kb dans l'ADN mitochondrial par PCR multiplex et analyse par buvardage de Southern. Conclusions : Selon les résultats de cette étude il existerait un défaut biochimique dans l'activité du complexe I et la production d'ATP, qui pourrait être dû à une accumulation de fer dans les mitochondries et pourrait influencer l'âge de début de l'AF.

Can. J. Neurol. Sci. 2009; 36: 26-31

Friedreich's ataxia (FRDA) is an autosomal recessive neurodegenerative disorder with an incidence of approximately 1 in 50,000. Friedreich's ataxia is characterized by progressive gait and limb ataxia, reduced tendon reflexes in the legs, loss of position sense, dysarthria, and pyramidal weakness of the legs. ${ }^{1}$ Hypertrophic cardiomyopathy is found in almost all patients and diabetes mellitus is seen in $10 \%$ of the patients. The age of onset is usually around puberty, almost always before 25 years with a slow progression of the disease. ${ }^{2}$ The chromosomal locus for FRDA (9q13) was reported in $1988^{3}$ and in $97 \%$ of FRDA patients there is an expansion of an unstable GAA trinucleotide repeat in intron 1 . Normal individuals have 7-34 repeats, while FRDA patients have expansions of 66 repeats or greater. ${ }^{4}$

The FRDA gene encodes a widely expressed 210 -aa protein, frataxin, which is located in mitochondria and is severely reduced in FRDA patients..$^{5}$ Although frataxin function is still unknown, yeast strains carrying a disruption in the Frataxin homologue gene (YFH1) showed a severe defect of mitochondrial respiration ${ }^{6-8}$ and loss of mDNA $^{7-9}$ associated with elevated intramitochondrial iron..$^{8-10}$

The five enzyme complexes of oxidative phosphorylation (OXPHOS) system are located in the mitochondrial inner

\footnotetext{
From the Genetic Group (MMH, MK), Biochemical Group (SH), Science School, Tarbiat Modares University; Department of Medical Genetic (MH), National Institute for Genetic Engineering and Biotechnology; Special Medical Center (MH);

Department of Neurology (SN), Medical Science, Tehran University, Tehran, Iran. Received June 25, 2008. Final Revisions Submitted August 5, 2008.

Correspondence to: Massoud Houshmand, Department of Medical Genetic, National Institute for Genetic Engineering and Biotechnology (NIGEB), Tehran, Iran.
} 
membrane and encoded by both the nuclear genome and the mitochondrial DNA (mtDNA). NADH ubiquinone reductase (complex I) is the first and one of the largest catalytic complexes. Complex I oxidize NADH of the mitochondrial matrix and reduce ubiquinone to generate part of the proton gradient required for Adensoine triphosphate (ATP) synthesis. Defects of this complex either alone or in combination with other complexes are probably the most frequently defect observed in the respiratory chain (RC). This predominance of complex I dysfunction suggests that its structure or function is relatively easily perturbed. ${ }^{11}$ Dysfunction of the mitochondrial complex I is shown in patients with neurological disease including Alzheimer disease (AD), ${ }^{12}$ Parkinson disease (PD) ${ }^{13}$ Multiple sclerosis (MS) ${ }^{14}$ and Friedreich's ataxia..$^{5,15}$

Adensoine triphosphate is universal in the metabolic processes of all living cells and the amount of ATP per cell remains reasonably constant in healthy cells. Currently, the bioluminescence assay using the firefly ATP-dependent luciferin-luciferase system is the most popular method for ATP determination due to its high sensitivity and specificity. ${ }^{16}$

In the present study, mtDNA deletions and complex I activity and intracellular ATP were assayed in lymphocytes from patients with FRDA. Since the isolation of platelets requires greater blood volumes than does the isolation of lymphocytes, analysis of the latter could represent an easier, less invasive, and less time-consuming method for assessing the role of oxidative metabolism in the pathogenesis of FRDA.

\section{Materials ANd Methods}

\section{Patients}

Twelve patients ( 7 females and 5 males), from nine unrelated families, with diagnosis of FRDA regarding clinical criteria of Harding and Geffroy et al ${ }^{1,2}$ (Table) and 25 healthy controls (15 females and 10 males) matched for age, sex and ethnicity were selected. All of the patients and control group were informed on the aims of the study and gave their informed consents for the genetic analysis. Patients were diagnosed and referred for assessment by consultant neurologists.

\section{Sizing of $G A A$ repeats}

The DNA was extracted from the patients' blood using a DNA extraction kit (DNAfast Kit-Genfanavaran, Tehran, Iran). A portion of the FRDA gene was amplified by using the Expand Long Template PCR System (Roche, Mannheim, Germany) and the 5200Eco (5'-GGG CTG GCA GAT TCC TCC AG-3') and 5200Not (5'-TAA GTA TCC GCG CCG GGA AC-3') primers previously described ${ }^{3}$. The GAA repeat length was calculated according to the size of the PCR product $(457+3 n \mathrm{bp}, \mathrm{n}=$ number of GAA triplets).

\section{MtDNA deletions and southern blotting analysis}

The multiplex PCR reactions were performed in a thermal cycler (MWG-Biotech Primus) as previously described. ${ }^{17}$ For Southern blotting total DNA (about $10 \mu \mathrm{g}$ ) was digested with restriction enzyme PvuII (Roche Diagnostics) to linearize the mtDNA. Subjected to electrophoretic analysis on a $0.7 \%$ agarose gel and transferred to nylon membrane. The blot was probed with a 1341 bp fragment from D-loop region [using ONP 206

\section{Table: Clinical data for FRDA patients}

\begin{tabular}{l|l|l|l|l|l|l|l}
\hline Case & $\begin{array}{l}\text { Age } \\
\text { (years) }\end{array}$ & $\begin{array}{l}\text { Disease } \\
\text { Onset } \\
\text { (years) }\end{array}$ & Sex & $\begin{array}{l}\text { GAA } \\
\text { repeats }\end{array}$ & $\begin{array}{l}\text { Foot } \\
\text { deformity }\end{array}$ & $\begin{array}{l}\text { hearing } \\
\text { loss }\end{array}$ & scoliosis \\
\hline P1 & 17 & 14 & F & 384 & Yes & No & Yes \\
P2 & 24 & 12 & F & 329 & NA & NA & Yes \\
P3 & 10 & 8 & F & 991 & Yes & Yes & No \\
P4 & 12 & 7 & M & 645 & Yes & No & Yes \\
P5 & 20 & 5 & F & 947 & Yes & No & Yes \\
P6 & 21 & 3 & M & 890 & Yes & Yes & Yes \\
P7 & 17.5 & 13 & M & 590 & Yes & NA & Yes \\
P8 & 23 & 15 & F & 498 & Yes & No & Yes \\
P9 & 23 & 8 & F & 878 & Yes & No & Yes \\
P10 & 20 & 13 & F & 760 & No & NA & Yes \\
P11 & 32 & 21 & M & 247 & Yes & Yes & Yes \\
P12 & 27 & 16 & M & 618 & Yes & Yes & Yes \\
Mean \pm SD & $20.5 \pm 5.51$ & $11.2 \pm 4.93$ & & $647 \pm 234$ & & & \\
\hline
\end{tabular}

NA $=$ Not Available

(15340-15360) and ONP 77 (110-91) primer pairs]. Southern blot analysis was performed using a DIG DNA labeling and Detection Kit (Roche, Mannheim, Germany).

\section{Isolation of Lymphocytes from Peripheral Blood}

Blood (5 mL) was diluted with Hank's solution at a ratio of 1:2 within one hour of extraction and slowly layered onto a 15$\mathrm{mL}$ screw-cap tube containing $5 \mathrm{~mL}$ Ficolymph (Bharafshan Co. Tehran, Iran.). The tubes were centrifuged for 20 minutes at 1000 $\times g$, after which the lymphocyte-containing layer was collected into a new centrifuge tube using a sterile pipette. The lymphocyte mix was then diluted in $10 \mathrm{~mL}$ Hank's solution and centrifuged for 10 minutes at $440 \times \mathrm{g}$. The supernatant was discarded, $5 \mathrm{~mL}$ of Hank's solution was added, the pellet was mixed gently in this buffer, and the mixture was allowed to sit for about 45 seconds (s). The mixture was gently pipetted and then centrifuged at $230 \times \mathrm{g}$ for 15 minutes. The supernatant was discarded, and the pellet was suspended in RPMI 1640 medium (Bharashan Co. Tehran, Iran) supplemented with L-glutamine.

\section{Complex I activity assay}

Fresh lymphocyte pellets (about $10^{6}$ cells) were homogenized by sonication in $20 \mathrm{mmol} / \mathrm{L}$ potassium phosphate buffer $(\mathrm{pH} 7.5)$ for $15 \mathrm{~s}$ (three bursts of $5 \mathrm{~s}$ each) at $30 \mathrm{~W}$ on ice. The final protein concentration was quantified according to Bradford's method. ${ }^{18}$ The homogenate, containing 2-4 g/L protein, was kept on ice and used for assay the same day. Biochemical studies were carried out on lymphocyte homogenate of 12 patients and 25 controls. NADH-ferricyanide reductase activity is also assayed spectrophotometrically by following the disappearance of 
oxidized ferricyanide at $410 \mathrm{~nm}$ and $30^{\circ} \mathrm{C} .{ }^{19}$ The assay mixture contained in $1 \mathrm{ml}$ : NADH, ferricyanide, triethanolamin and phosphate buffer (PH 7.8). The reaction was started by the addition of the lymphocyte homogenate ${ }^{20}$.

\section{Extraction of intracellular ATP and its measurements}

The lymphocyte cells (about 106 cells) were pelleted in a microcentrifuge tube by centrifugation at $12,000 \mathrm{~g}$ for $10 \mathrm{~min}$. The cellular ATP was then extracted by adding $0.5 \mathrm{ml}$ water and boiling the cell pellet for $5 \mathrm{~min}$. After vortexing and centrifugation $\left(12,000 \mathrm{~g}\right.$ for $5 \mathrm{~min}$ at $\left.4^{\circ} \mathrm{C}\right), 50 \mu \mathrm{l}$ of the supernatant was used for bioluminescence measurement. The standard curve of ATP was obtained by serial dilutions of $4 \mathrm{mM}$ ATP solution $(0.25,0.5,1.0,2.0$, and 4.0). Light emission was measured with a Sirius tube luminometer, Berthold defection system (Germany). After calibration against the ATP standard, the ATP content of the cell extract was determined.

\section{Statistical analysis of data}

Fisher's exact probability test was used to examine the association between two groups. Values of $\mathrm{P}<0.05$ were regarded as statistically significant. Statistical analysis was performed using the GraphPad Prism software.

\section{RESULTS}

The age range of patients and controls were 10-32 and 12-34 years, respectively. Mean age of FRDA onset and becoming wheelchair-bound were 11.2 $\pm 4.93($ Mean \pm SD) and $15.7 \pm 2.31$ $(\mathrm{Mean} \pm \mathrm{SD})$ years. The $(\mathrm{GAA})_{\mathrm{n}}$ repeats on FRDA patients were observed in both alleles, ranging from 247 to 991 GAA motifs $(647 \pm 234$, Mean \pm SD). The mean value of expanded alleles was 564 repeats for allele 1 (Smaller allele) and 730 for allele 2 (Larger allele). Patients with GAA expansion repeats, more frequently showed absence tendon reflexes and abnormalities in: (a) position and vibration sense, (b) feet (Pes Cavus), and (c) ECG findings. Comparison of the age of onset with the GAA repeats demonstrated a statistically significant inverse correlation $(\mathrm{r}=-0.8, \mathrm{n}=12$; Figure $3 \mathrm{a})$.

In this study, all patients and controls were screened for mtDNA deletion using the multiplex PCR, southern blotting and sequencing. The size of deletions was $\sim 8.6$ and $9 \mathrm{~kb}$ in 9 patients out of $12(75 \%)$ (Figure 1). Deletions mostly occurred in the region between np 5461 and np 15,000. Healthy controls showed no deletions in their mtDNA.

Complex I activity (NADH-ferricyanide reductase) were assayed in lymphocyte homogenates from FRDA patients and the controls. Repeated assays $(n=3)$ of the same lymphocyte homogenates (control subjects and patients) gave highly reproducible results, both within the same day (single samples). Figure 2a, shows that the activities of NADH-ferricyanide reductase are significantly lower in patients than in control subjects $(\mathrm{P}=0.001)$. Results were expressed as nmol. $\mathrm{Min}^{-1} \cdot \mathrm{mgprotein}^{-1}$. Mean value for control subjects $(\mathrm{n}=25)$ and patients $(\mathrm{n}=12)$ were $119.42 \pm 13.48$ and $85.751 \pm 7.5$ $(\mathrm{Mean} \pm \mathrm{SD})$, respectively.

The cellular contents of ATP were measured by preparing an ATP calibration curve. Using the cell count of the samples together with an estimate of the cell volume, the intracellular concentration of ATP was calculated. Figure $2 b$ shows that the

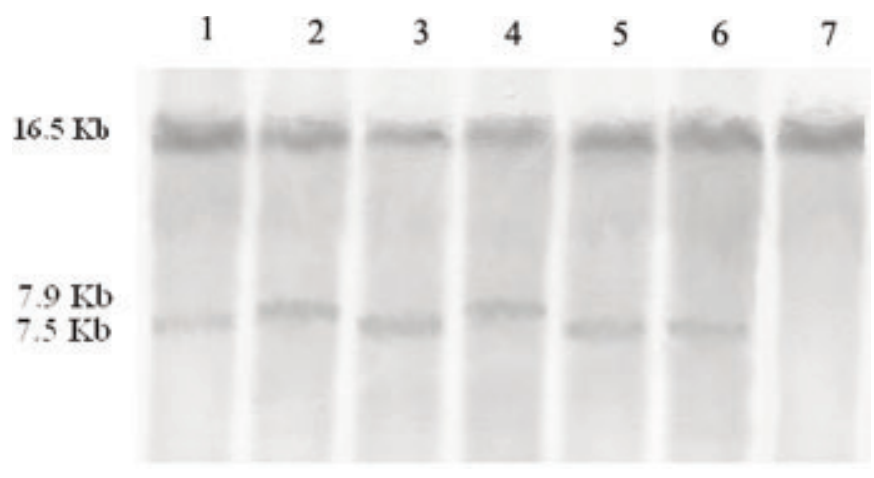

Figure 1: Southern blot analysis of mtDNA deletion. Lanes 1, 3, 5 and 6 show $9 \mathrm{~kb}$ deletion and lanes 2 and 4 show $8.6 \mathrm{~kb}$ in mtDNA of FRDA patients, lane 7 is control (without deletion).

a

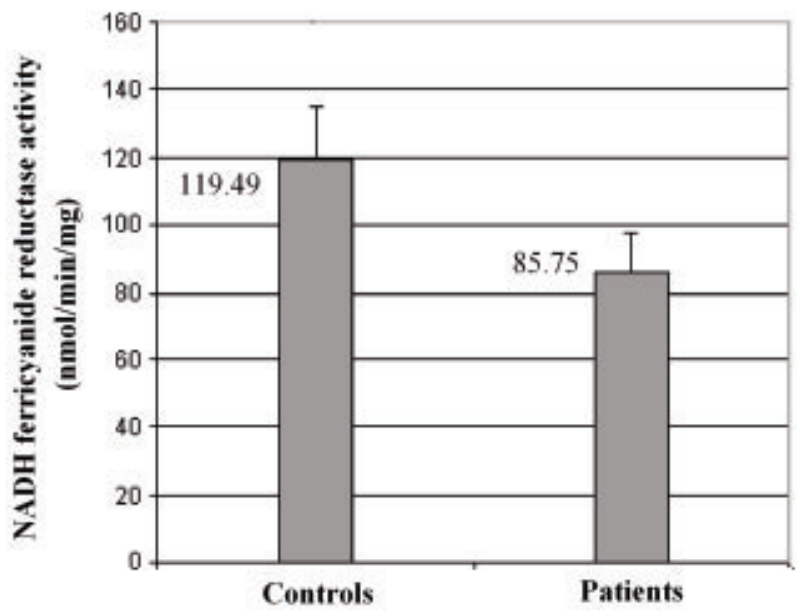

b

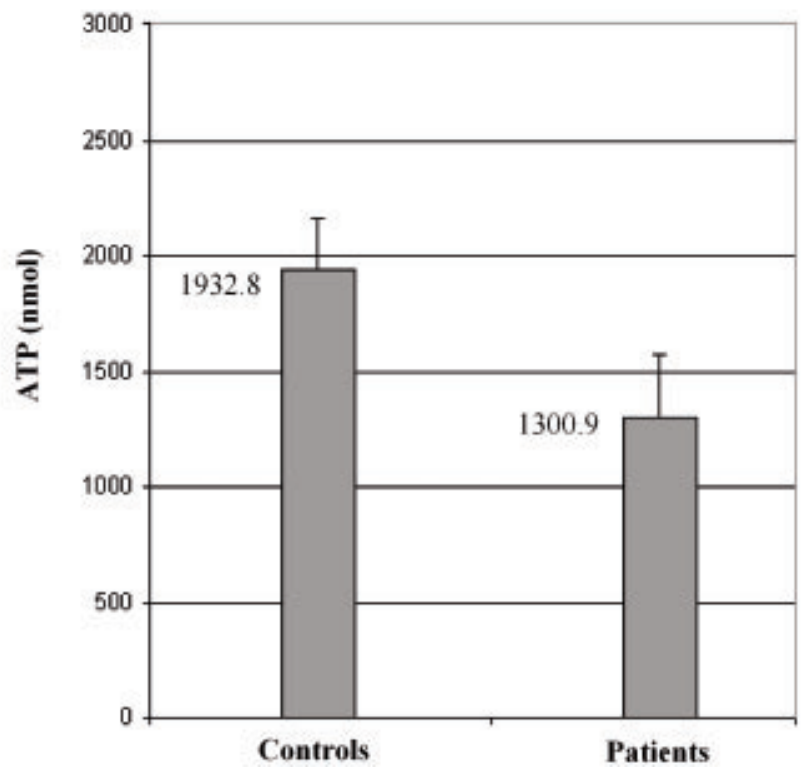

Figure 2: $a, b)$ Bar diagram showing the activity of complex I and intracellular ATP content in lymphocytes from control subjects and FRDA patients, respectively. Activity of complex I and intracellular ATP were significantly reduced in patients with FRDA and control subjects. 
a

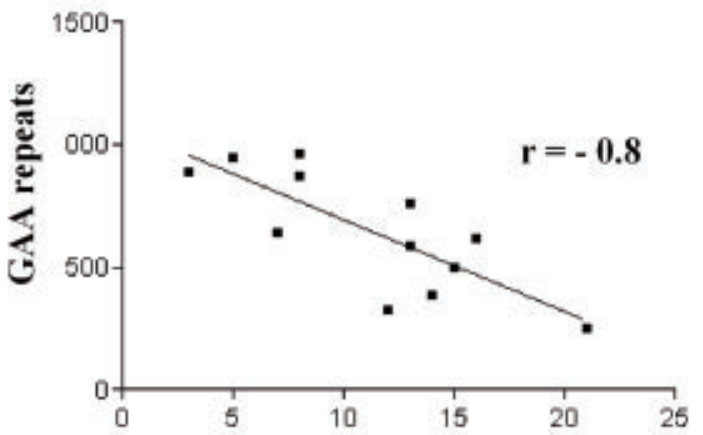

b

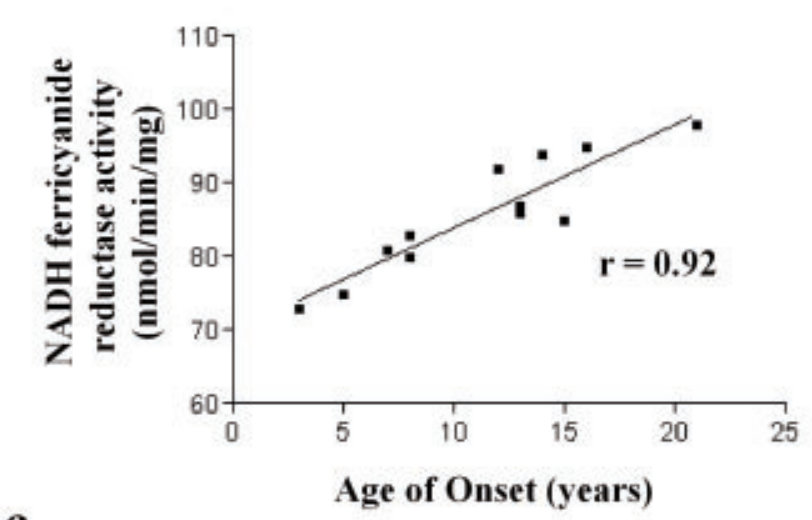

c

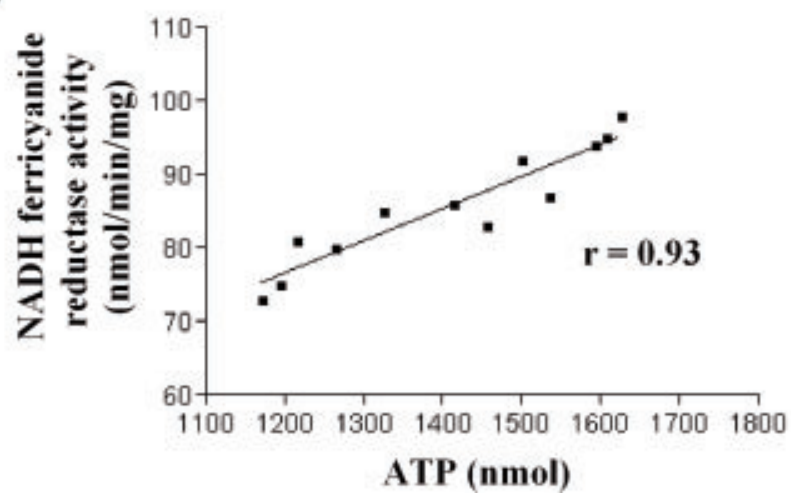

Figure 3: $a, b)$ Correlation between age at onset, GAA repeats, and complex I activity in FRDA patients. c) Correlation between complex I activity and Intracellular ATP content in lymphocyte from FRDA patients.

cellular contents of ATP are significantly lower in patients than in control subjects $(\mathrm{P}=0.001)$. Results were expressed as $\mu \mathrm{mol}$ ATP. Mean value for control subjects $(\mathrm{n}=25)$ and patients $(\mathrm{n}=12)$ were $1932.84 \pm 177.87$ and $1300.9 \pm 169.42(\mathrm{Mean} \pm \mathrm{SD})$, respectively.

\section{Discussion}

The expansion of the GAA repeat in intron 1 of the FRDA gene results in a reduction of frataxin expression. Peripheral blood leukocytes of FRDA patients have a residual level of frataxin mRNA ranging between $13 \%$ and $30 \%$ and FRDA carriers have levels which are approximately $40 \%$ of controls. Asymptomatic carriers also show reduced frataxin mRNA levels. ${ }^{21}$ The mounts of residual frataxin in lymphoblastoid cell lines from Friedreich's ataxia patients varies between reports from 4 to $29 \%^{22}$ and 6 to $8 \%{ }^{23}$ of the level in normal controls.

The size of GAA expansion observed in our patients $(647 \pm 234$ GAA units, Mean \pm SD) reflects the instability of this expansion during transmission. We observed strong inverse correlation $(\mathrm{r}=-0.8)$ between GAA expansion size and age of onset in our patients.

Large-scale deletions of mtDNA are frequently found in the affected tissues of patients with mitochondrial myopathy ${ }^{24}$ or elderly subjects..$^{25}$ The $\sim 8.6$ and $9.0 \mathrm{~kb}$ deletions cause a loss or truncation of the structural genes of ATPase 6/8, COIII, ND3, ND4L, and ND4, ND5, ND6, Cytb and eight tRNA genes and probably have a strong effect on the oxidative phosphorylation (OXPHOS) and alter ATP production. These deletions in FRDA patients may result in multiple respiratory chain deficiencies. ${ }^{26}$ To evaluate the deleted mtDNA, we carried out southern-blot analysis of mtDNA from patients presenting deleted mtDNA by PCR screening procedure. Defective respiratory enzymes containing protein subunits encoded by the deleted mtDNA may further enhance free radical production, resulting in more profound oxidative damages in FRDA patients.

Frataxin is a component of the human $\mathrm{Fe} / \mathrm{S}$ cluster (ISC) assembly machinery and it plays a role in the maturation of both mitochondrial and cytosolic $\mathrm{Fe} / \mathrm{S}$ proteins and also in heme biosynthesis. ${ }^{27}$ Recently, it has been shown that Frataxin interacts with mitochondrial electron transport chain proteins. ${ }^{28}$ Excess iron in mitochondria of FRDA patients can cause mitochondrial dysfunction through irreversible oxidative damage. Iron is a well-known catalyst of free radicals. Iron accumulation in the mitochondria of patients with FRDA would result in hypersensitivity to oxidative stress as a consequence of Fenton reaction. $\left(\mathrm{Fe}^{+2}\right.$-catalyzed production of hydroxyl radicals). As reactive oxygen species (ROS) are continuously generated by the respiratory chain, they may cause significant oxidative damage to mtDNA, (for example mtDNA deletions or mutations) if not efficiently eliminated. In the presence of mtDNA deletions, which may caused as mentioned by ROS or free radicals generated during aerobic metabolism, sensitive cells as skeletal muscles are deprived of ATP (due to the defective respiratory functions of mitochondria) and then they run into a state of energy crisis through a 'vicious cycle' as proposed by. ${ }^{29}$

In this study, complex I activity was measured by using of ferricyanide as an artificial electron acceptor from a site on complex I. We found that catalytic activity of complex I was significantly decreased in FRDA patients compared with control subjects $(\mathrm{p}=0.001)$. A statistically significant correlation $(\mathrm{r}=0.92)$ between onset of FRDA and complex I activity was also observed (Figure $3 b$ ).

Factors that may affect Complex I function have been classified in several subclasses. Decreased activity of complex I can be the result of mtDNA gene mutation, mutation of nuclear genes and acquired defect with free radicals. The mechanisms causing decrease of activity remain unknown. To determine reasons for decreasing activity in complex I and its involvement 
in pathogenesis of FRDA, we should screen mtDNA genes (protein-encoding genes, tRNA genes and rRNA genes) to find mutations of mtDNA.

Adensoine triphosphate, the "energy currency" of the cell, plays a central role in bioenergetics. ${ }^{30,31}$ Intracellular ATP of lymphocytes is significantly decreased in FRDA patients compared with control subjects $(p=0.001)$. In addition, we calculated the effect of complex I activity on intracellular ATP content, and found a statistical significant between them $(\mathrm{r}=$ 0.93, $\mathrm{P}<0.002$; Figure 3c).

Our data convincingly show that age at onset is strongly dependent on the size of GGA expansion, Complex I and intracellular ATP content. We suggest that decreased frataxin expression (GAA expansion repeats) in FRDA cells results in increased mitochondrial iron and increased free iron levels resulting in free radical generation, leading to oxidative damage including increased mtDNA mutation and decreased complex I activity. When complex I activity decreases, it will impair ATP synthesis, and cellular ATP content. Nervous system, skeletal muscles and heart tissues require large amounts of ATP and an important requirement in the function of these tissues is accessibility $\mathrm{ATP}^{32}$. Since FRDA patients have ataxia, diabetes mellitus and cardiomyopathy, it may be a dysfunction of complex I and other complexes in mitochondria and decreased intracellular ATP which are involved in these manifestations.

Functional defects of the complex I was reported by others in muscle and brain of FRDA patients. ${ }^{15,33}$ Here, we report that such defects also occur in lymphocytes of patients with FRDA. Our results also indicate that lymphocyte analysis provides an easy, noninvasive method for investigating respiratory chain enzymes and assessing mitochondrial function in patients with FRDA.

\section{ACKNOWLEDGEMENT}

This research was supported by Tarbiat Modares University. We thank all patients for providing blood samples for scientific research as well as Special Medical Center (Tehran, Iran), whose cooperation and support is essential in our work. The study was approved by National Institute for Genetic Engineering and Biotechnology Human Research Ethics committee.

\section{REFERENCES}

1. Harding AE. Friedreich's ataxia: a clinical and genetic study of 90 families with an analysis of early diagnostic criteria and intrafamilial clustering of clinical features. Brain. 1981;104: 589-620.

2. Geffroy G, Barbeau A, Breton G. Clinical description and roentgenologic evaluation of patients with Friedreich's ataxia. Can J Neurol Sci. 1976;3:279-86.

3. Campuzano V, Monermini L, Molto MD, Pianese L, Cossee M, Cavalcanti F, et al. Friedreich's ataxia: autosomal recessive disease caused by an intronic GAA triplet repeat expansion. Science. 1996;271:1423-7.

4. Cossee M, Schmitt M, Campuzano V, Reutenauer L, Moutou C, Mandel JL, et al. Evolution of the Friedreich's ataxia trinucleotide repeat expansions: founder effect and permutations. Proc Natl Acad Sci USA. 1997;94:7452-7.

5. Bradley J, Blake JC, Chamberlain S, Thomas PK, Cooper JM, Schapira AHV. Clinical Biochemical and molecular genetic correlations in Friedreich's ataxia. Hum Mol Genet. 2000;9(2): 275-82.

6. Wilson RB, Roof DM. Respiratory deficiency due to loss of mitochondrial DNA in yeast lacking the frataxin homologue. Nat Genet. 1997;16:352-7.
7. Ramazzotti A, Vanmansart V, Foury F. Mitochondrial functional interactions between frataxin and Isulp, the iron-sulfur cluster scafold protein, in Saccharomyces cerevisiae. FEBS Letters. 2004;557:215-20.

8. Foury F, Talibi D. Mitochondrial control of iron homeostasis. A genome wide analysis of gene expression in a yeast frataxin deficient mutant. J Biol Chem. 2000;276:762-8.

9. Foury F, Cazzalini O. Deletion of the yeast homologue of the human gene associated with Friedreich's ataxia elicits iron accumulation in mitochondria. FEBS Letters. 1997;411:373-7.

10. Babcock M, de Silva D, Oaks R, Davis-Kaplan S, Jiralerspong S, Montermini L, et al. Regulation of mitochondrial iron accumulation by Yfh1, a putative homolog of frataxin. Science. 1999;276:1709-12.

11. Cooper JM, Mann VM, Krige D, Schapira AHV. Human mitochondrial complex I dysfunction. Biochim Biophys Acta. 1992;1101:198-203.

12. Kish SJ, Bergeron C, Rajput A, Dozic S, Masdrogiacomo F, Chang, $\mathrm{L}$, et al. Brain cytochrome oxidase in Alzheimers disease. J Neurochem. 1992;59:776-9.

13. Schapira AHV, Cooper JM, Dexter D, Clark JB, Jenner P, Marsden CD. Mitochondrial complex I deficiency in Parkinsons disease. J Neurochem. 1990;54:823-7.

14. Lu F, Selak M, O'Connor J, Croul S, Lorenzana C, Butunoi C, et al. Oxidative damage to mitochondrial DNA and activity of mitochondrial enzymes in lesions of multiple sclerosis. J Neurol Sci. 2000;177:95-103.

15. Rotig A, de Lonlay P, Chretien D, Foury F, Koenig M, Sidi D, et al. Aconitase and mitochondrial iron-sulphur protein deficiency in Friedreich ataxia. Nat Genet. 1997;17:215-7.

16. Stanly P, Williams SG. Use of the liquid scintillation spectrometer for determining adenosine triphosphate by the luciferase enzyme. Anal Biochem. 1969;29:381-92.

17. Houshmand M, Shariat Panahi SM, Nafisi S, Soltanzadeh A, Alkandari FM. Identification and sizing of GAA trinucleotide repeat expansion, investigation for D-loop variations and mitochondrial deletions in Iranian patients with Friedreich's ataxia. Mitochondrion. 2006;6:87-93.

18. Bradford MM. A rapid and sensitive method for the quantitation of microgram quantities of protein utilizing the principle of proteindye binding. Anal Biochem. 1976;72:248-54.

19. Dooijewaard G, Slater ES. Steady-state kinetics of high molecular weight (Type-I) NADH dehydrogenase. Biochim Biophys Acta. 1976;440:1-15

20. Hatefi Y, Hanstein WG. Interactions of reduced and oxidized triphosphopyridine nucleotides with the electron-transport system of bovine heart mitochondria. Biochemistry. 1973;12: 3515-22.

21. Pianese L, Turano M, Lo Casale MS, De Biase I, Giacchetti M, Ponticelli A, et al. Real time PCR quantification of frataxin mRNA in the peripheral blood leucocytes of Friedreich's ataxia patients and carriers. J Neurol Neurosurg Psychiatry. 2004;75: 1061-3.

22. Campuzano V, Montermini L, Lutz Y, Cova L, Hindelang C, Jiralerspong $\mathrm{S}$, et al. Frataxin is reduced in Friedreich ataxia patients and is associated with mitochondrial membranes. Hum Mol Genet. 19976;1771-80.

23. Turano M, Tammaro A, De Biase I, Lo Casale MS, Ruggiero G, Monticelli, et al. 3-Nitropropionic acid increases frataxin expression in human lymphoblasts and in transgenic rat PC12 cells. Neurosci Lett. 2003;350:184-6.

24. Holt IJ, Harding AE, Cooper JM, Schapira AH, Toscano A, Clark $\mathrm{JB}$, et al. Mitochondrial myopathies: clinical and biochemical features of 30 patients with major deletions of muscle mitochondrial DNA. Ann Neurol. 1989;29:699-710.

25. Yen TC, Su JH, King KL, Wei YH. Aging-associated 5 kb deletion in human liver mitochondrial DNA. Biochem Biophys Res. 1991;178:124-31.

26. Lee HC, Wei YH. Mutation and oxidative damage of mitochondrial DNA and defective turnover of mitochondria in human aging. J Formos Med Assoc. 1997;96:770-8. 
27. Stehling O, Elsasser HP, Bruckel B, Muhlenhoff U, Lill R. Ironsulfur protein maturation in human cells: evidence for a function of frataxin. Hum Mol Genet. 2004:13(23):3007-15.

28. Gonzalez-Cabo P, Vazquez-Manriue RP, Garcia-Gimeno MA, Sanz $\mathrm{P}$, Palau F. Frataxin interacts functionally with mitochondrial electron transport chain proteins. Hum Mol Genet. 2005; 14(15):2091-8

29. Wei YH. Oxidative stress and mtDNA mutations in human evolution and disease. Proc Natl Acad Sci. 1998;217:53-63.

30. Garlnad JM, Halestrap A. Energy metabolism during apoptois. J Biol Chem. 1997;272:4680-8.
31. Nakamura N, Wada Y. Properties of DNA fragmentation activity generated by ATP depletion. Cell Death Differ. 2000;7:477-84.

32. Holmgrena D, Wahlandera H, Erikssona BO, Oldforsb A, Holmec E, Tuliniusd M. Cardiomyopathy in children with mitochondrial disease. Eur Heart J. 2003;24:280-8.

33. Lodi R, Cooper JM, Bradley JL, Manners D, Styles P, Taylor DJ, et al. Deficit of in vivo mitochondrial ATP production in patients with Friedreich ataxia. Proc Natl Acad Sci USA. 1999;96: 11492-5. 